\title{
A Primer on Release-Rate Testing of Semisolids
}

Royal Hanson, CEO

e-mail:rhanson@hansonresearch.com

Hanson Research Corporation, 9810 Variel Ave., Chatsworth, CA 91311

W hereas traditional oral dosage formulations are assimilated into the body through the GI tract, many topical formulations are designed to permeate through the skin. This presents significant challenges in release-rate testing. What type of apparatus best replicates the dynamics of drug permeation through the skin? What quality control tool provides the analyst with reliability and consistency in results while still discriminating critical variances in semisolid formulations?

Oral dosage formulations undergo disintegration and dissolution throughout the GI tract and assimilation into the bloodstream (Figure 1). Topical formulations release drug API through permeation of the skin for pharmacological response. Topical and transdermal medications have been designed for both local and systemic effect. Oral and topical dosage forms provide different avenues of drug introduction and thus suggest different approaches in release-rate testing.

Human skin is a natural barrier to outside agents (Figure 2). Drug substances administered through semisolid preparations (creams, ointments, and gels) must penetrate the layers of the skin to have benefit. An appropriate in vitro apparatus for release-rate testing of topical products will mimic skin permeation kinetics, including donor, membrane, and a receptor medium that is analyzed for drug concentration.

Diffusion cells are widely used for release-rate testing of semisolids. The pioneering work of Dr.T.J. Franz in the 1970s led to the basic apparatus configuration of a small-volume, jacketed cell with a donor chamber for drug application, a membrane through which it may permeate, and a receptor chamber from which samples may be analyzed for drug release (Figure 3). This popular device is often referred to as the "Franz cell."

The vertical diffusion cell (VDC) represents a refinement of the early Franz cell. It is based on several decades of application and may be used for release-rate testing of creams, ointments, and gels (Figure 4). Appropriate membrane and receptor media selections are critical decisions in method development. The U.S. FDA SUPAC-SS guidance (1997) recommends the VDC for assessing scaleup and post-approval changes in topical formulations. Diffusion cells are available from Hanson Research (Chatsworth, CA), PermeGear (Hellertown, PA), and others.

Similar to USP dissolution apparatus, a diffusion cell tester typically includes a grouping of six cells for the simultaneous release-rate testing of six specimens (Figure 5). A cell drive controls the mixing of each cell receptor chamber throughout the test, and a circulating bath provides heated water to the jacketed cells to maintain a constant temperature (typically $32{ }^{\circ} \mathrm{C}$ for skin applications). Samples are manually withdrawn, and the receptor medium is manually replaced to maintain a constant media-membrane interface.

Diffusion cell testing may be automated with a programmable sampler and collector. Some method protocols run overnight or even days, and automation provides the convenience and efficiency of unattended sample runs. A precision syringe-pump sampler is illustrated (Figure 6). Method protocols are programmed for automatic sampling, replenishment of receptor media, and collection into sealed HPLC vials for analysis.

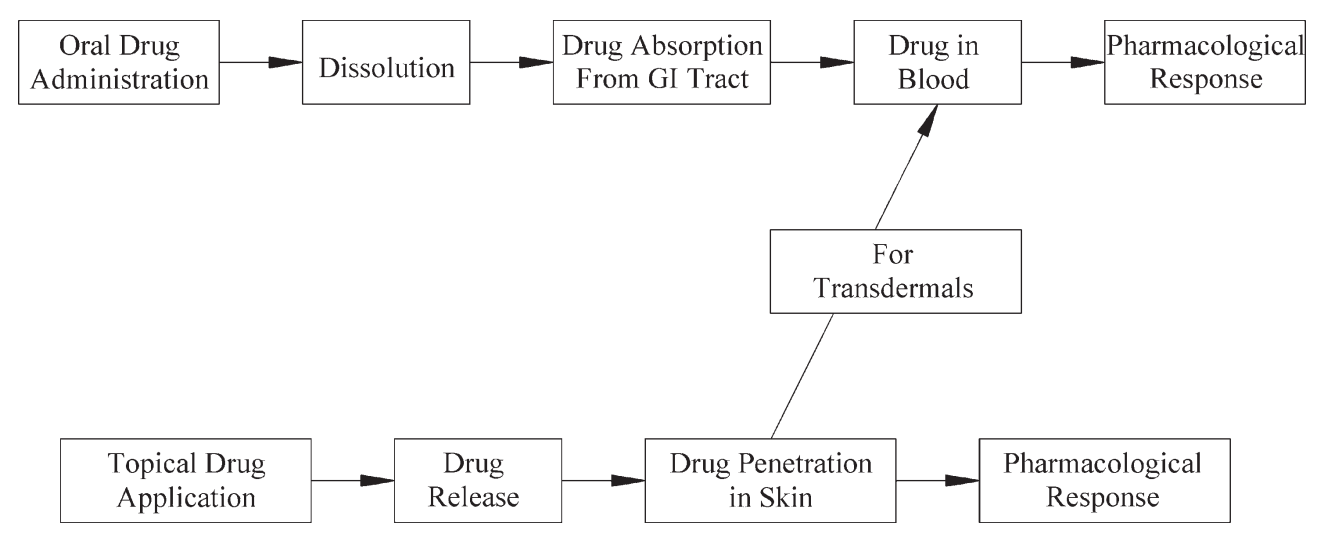

Figure 1. Comparison of oral and topical drugs. 

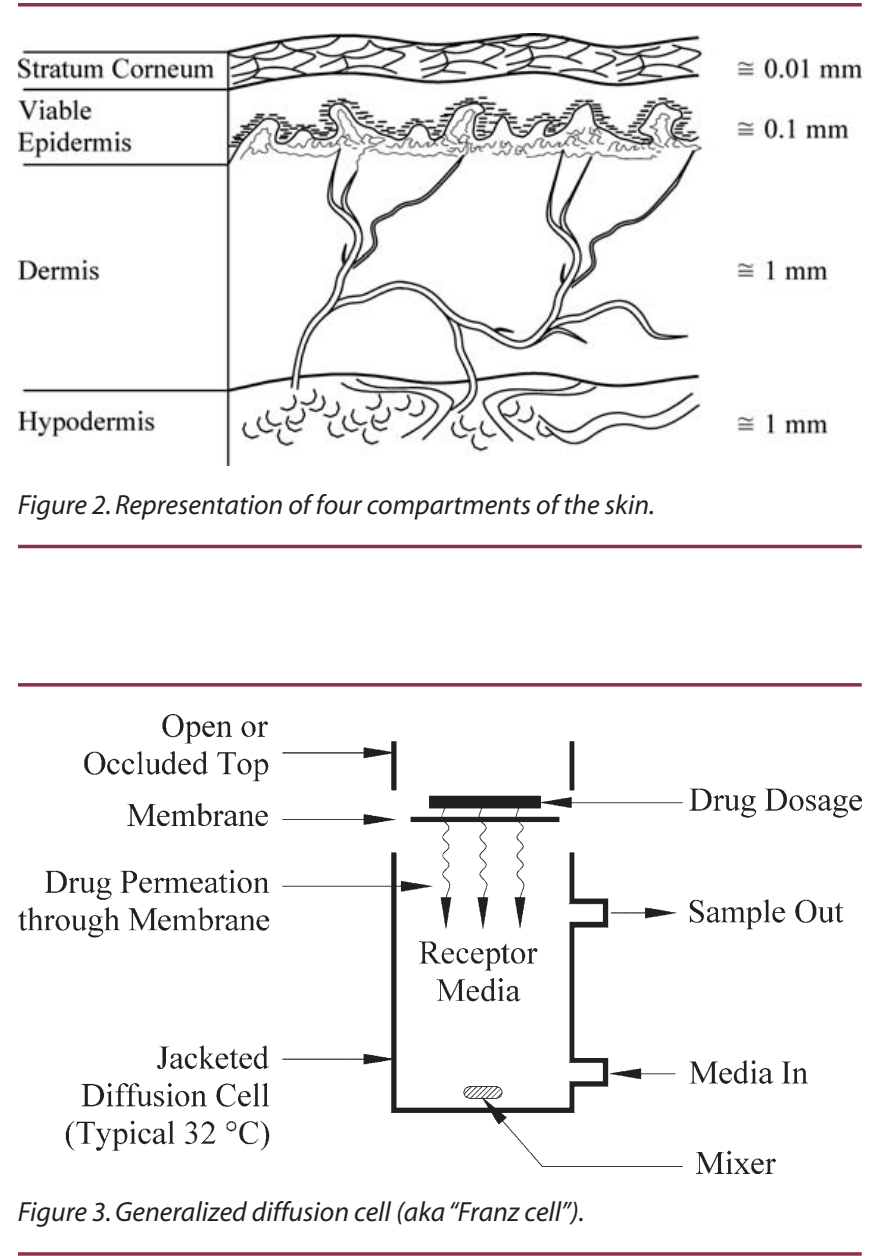

Peristaltic and piston pumps have also been used for diffusion cells.

A modified holding cell has also been developed for release-rate testing of semisolids (Figure 7). This device, which is an adaptation of USP Apparatus 2, employs a special small-volume vessel and mini-paddle. The modified holding cell includes a donor chamber for topical drug application, sealed with a selected membrane, which is then immersed in the vessel media. The Hanson "ointment cell" is illustrated; another popular device is the Varian "enhancer cell."

A USP advisory panel and expert committee are currently evaluating appropriate compendia guidelines for testing semisolids. Proposed USP General Chapter $<3>$ Topical and Transdermal Drug Products: Quality Tests will be published in Pharmacopeial Forum (PF) 36 (6). Proposed General Chapter <1724> Topical and Transdermal Drug Products: Performance Tests is being finalized by the USP General Chapters of Pharmaceutical Dosage Forms Expert Committee and will be published in an upcoming issue of Pharmacopeial Forum for industry comment.
Useful for

- Skin Permeation

- Patch Studies

- Topicals and Skin Care

Products

Variations

- Volume (7 mL Typical)

- Membrane Area (15 mm-Dia. Typical)

- Media Composition

- May Be Automated

Figure 4. Vertical diffusion cell (VDC).

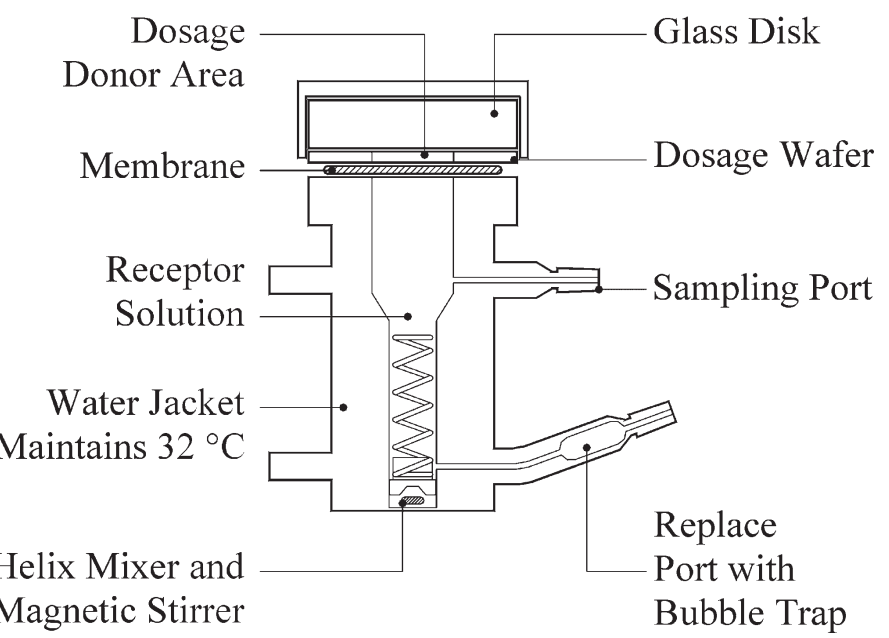

Helix Mixer and Bubble Trap 


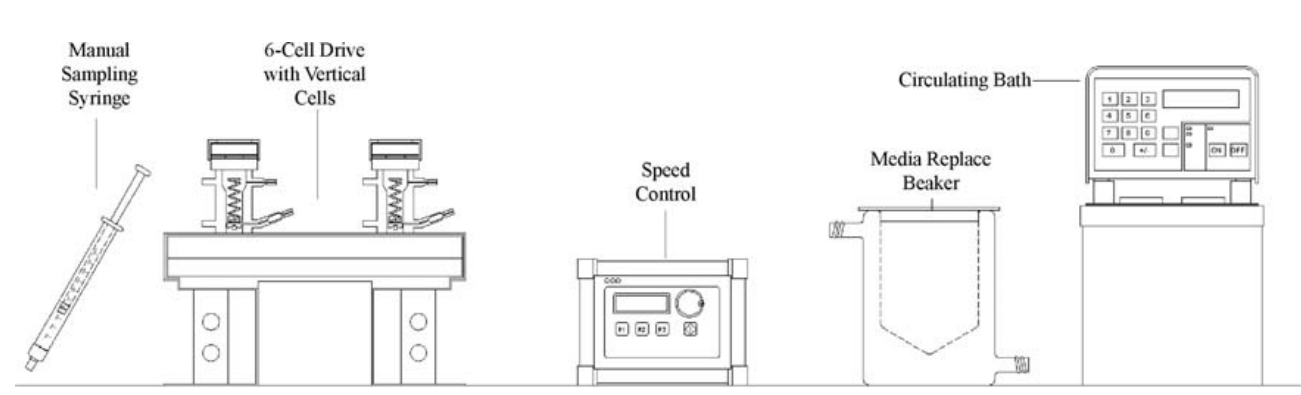

Figure 5. Manual diffusion cell system.

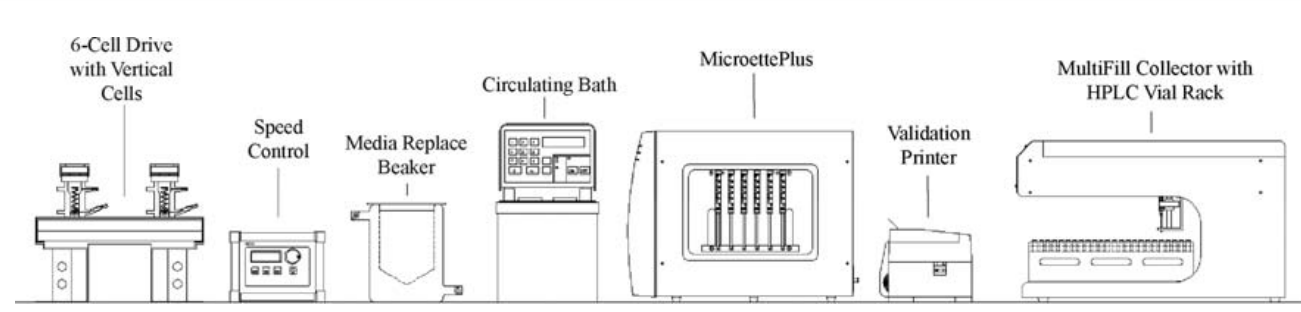

Figure 6. Automated diffusion cell system.

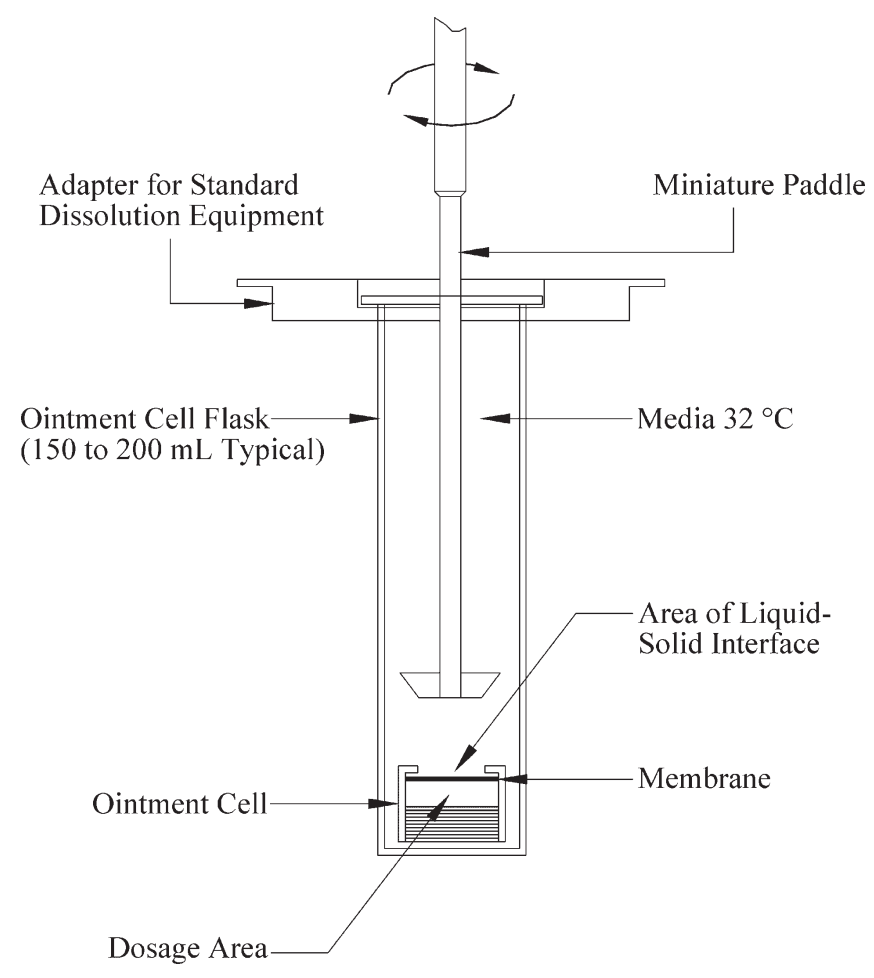

Figure 7. Modified holding cell for semisolids. 